Article

\title{
Complementary Relationship and Dual Crop Coefficient Approach-Based Study on Green Water Separation
}

\author{
$\mathrm{Na} \mathrm{Fu}{ }^{1}$, Xiaoyu Song ${ }^{1, *}, \mathrm{Lu} \mathrm{Xia}^{1}$, Lanjun $\mathrm{Li}^{1}$, Huaiyou $\mathrm{Li}^{2}$ and Yaolin $\mathrm{Li}^{2}$ \\ 1 State Key Laboratory of Eco-hydraulics in Northwest Arid Region of China, Xi'an University of Technology, \\ Xi'an 710048, China; fnsnow@163.com (N.F.); wulingjiaolp@163.com (L.X.); li_lanjun@126.com (L.L.) \\ 2 Xifeng Scientific Experiment Station of Soil and Water Conservation, Yellow River Conservancy Committee, \\ Qingyang 745000, China; qyxflhy@sohu.com (H.L.); hwyaolin@126.com (Y.L.) \\ * Correspondence: songxy@xaut.edu.cn; Tel.: +86-135-7259-3963
}

Received: 16 January 2019; Accepted: 19 February 2019; Published: 22 February 2019

check for updates

\begin{abstract}
Separating productive green water from non-productive green water could determine the potential for improving green water use through water-to-vapor conversion and the optimization of green water resource management. This study selected three typical planted forests of Robinia pseudoacacia, Platycladus orientalis, and Pinus tabulaeformis in the Nanxiaohegou sub-basin, a typical small sub-basin located in the gully region of the Loess Plateau. A combination of field monitoring, hydrological models, and statistical tests was used to obtain the crop coefficient and to differentiate productive green water from non-productive green water, based on the hydrological, climatic, and ecological processes in the basin. The results demonstrated that the complementary relationship areal evapotranspiration (CRAE) model was the most effective complementary relationship-based model for the simulation. Based on the calibrated parameters, it could be used for the simulation of green water flux of different vegetation types in the studied region. In the Nanxiaohegou sub-basin, the amounts of productive green water, non-productive green water, and total green water flux of $R$. pseudoacacia were the highest among all three types of vegetation, followed by those of $P$. orientalis and P. tabulaeformis forests during the growing seasons between 2015 and 2017.
\end{abstract}

Keywords: green water separation; water balance; dual crop coefficient; complementary relationship-based model; applicability evaluation

\section{Introduction}

The Swedish hydrologist, Falkenmark, at the Water and Soil Conference of the World Food and Agriculture Organization (FAO), introduced the concept of green water in 1995 by. It is defined as the soil water for plant growth, which will eventually evaporate into the atmosphere, including the water consumption of forests, grasslands, wetlands, and farmlands. It is the primary water source for the soil-plant system in terrestrial ecosystems [1]. Green water has gained considerable global recognition in recent years, and the concept has been cited and refined by other scholars [2-4]. Rockström [5] categorized green water into two components. The first is plant transpiration, which is the necessary water consumption for plant growth and biomass formation, namely productive green water; the other is the evaporation from the soil surface, including soil evaporation and plant interception, which is called non-productive green water. By separating productive green water and non-productive green water, ineffective evapotranspiration and its proportion can be distinguished from that of effective evapotranspiration. In this way, it is possible to determine the potential for increasing green water use through water-to-vapor conversion and the optimization of green water resource management, which are of great significance for improving water-use efficiency in terrestrial ecosystems [6]. 
In recent years, research in green water separation has made some progress. Bulcock et al. [7] compared the productive green water-use efficiency of Podocarpus henkelii with Pinus patula in the KwaZulu-Natal Midlands in South Africa. Lawrence et al. [8] described a series of simple modifications to the Community Land Model version 3 (CLM3) hydrology and vegetation parameterizations that could substantially improve the partitioning of evaporation and transpiration (ET) in both offline and coupled configurations through reduced canopy interception, increased soil moisture availability for transpiration, and increased soil moisture storage. Liu [9] used the GIS-based Environmental Policy Integrated Climate (GEPIC) model to estimate soil evaporation and plant transpiration and then studied the components of green water flux in Chinese farmland. Xu [10] introduced the green water coefficient in order to study the productive green water in the Middle Yellow River basin in China and found that, in order to obtain a comprehensive assessment of water resources, it was necessary for the evaluation system to include productive green water as part of the water resources in the basin where water conservation measures were under implementation. Lin et al. [11] pointed out that more attention should be paid to the evaluation of productive green water in agricultural practice, particularly for research into productive green water in small or medium-scale basins. Therefore, further studies are needed for the separation of regional productive green water and non-productive green water.

Hydrologically, green water flux is influenced by hydrothermal conditions and by vegetation conditions and underlying surface factors, such as soil moisture [12]. The traditional method for measuring the amount of green water is the water balance approach, which estimates the amount of green water by calculating the difference in water recharge and extraction in a region, and this has gained wide application in practice. However, it cannot reveal the dynamic process of green water and the effects of various factors that affect and control green water. Neither can it provide the physical and ecological characteristics of the vegetation or obtain a reliable amount of green water over a short period [13]. Bouchet [14] proposed the complementary relationship between the actual and potential evapotranspiration of the soil surface, which links the complex interactions between soil, vegetation, and the atmosphere system with the change pattern of meteorological factors, such as temperature, humidity, and radiation balance value, providing a new approach for regional green water calculation. The commonly used complementary relationship models include the complementary relationship areal evapotranspiration (CRAE), advection-aridity (AA), and the Granger model. When using these models to estimate green water on a monthly, daily, or hourly timescale, only conventional meteorological data are needed [15]. Moreover, the parameters of these models do not temporally or spatially vary, allowing them to be widely used. Combined with the dual crop coefficient approach that was recommended by FAO [16], regional vegetation transpiration can be calculated and productive green water can be differentiated from non-productive green water.

The Loess Plateau in North China is known for large-scale erosion processes, which are strongly enhanced by human impact in that area that lasts for thousands of years. At the same time, China allocates considerable efforts to control the erosion, among others, by large-scale programs of tree planting. This research selected three typical planted forests of Robinia pseudoacacia, Platycladus orientalis, and Pinus tabulaeformis in the Nanxiaohegou sub-basin, a typical small sub-basin in the gully region of the Loess Plateau. Based on the field monitoring of the growing season (May to September) in the Nanxiaohegou sub-basin between 2015 and 2017, this research calculated the green water resources of three typical artificial forests with the water balance approach for closed watershed. A combination of soil water content, soil evaporation, and plant interception that was observed from experimental measurements was used to differentiate productive green water from non-productive green water on a monthly timescale for different types of vegetation. Combined with the dual crop coefficient method and the Penman-Monteith formula recommended by FAO-56, the basal crop coefficient $\left(K_{c b}\right)$, soil evaporation coefficient $\left(K_{e}\right)$, and crop coefficient $\left(K_{c}\right)$ of the three forests in each month during the growing season were obtained. The complementary relationship theory-based hydrological models of CRAE, AA, and Granger were selected to simulate the green water flux on a weekly timescale. Subsequently, the three 
models were evaluated with the consistency coefficient, Nash-Sutcliffe coefficient, root-mean-square error, and normalized root-mean-square error to find the optimal model. The parameters of the optimal model were calibrated for three different artificial forests. Finally, by using the crop coefficient, green water flux at a daily timescale was separated. This is significant for the improvement of water-use efficiency in terrestrial ecosystems. This research contributes to the understanding of the green water cycle and it provides a theoretical basis for ecological and environmental restoration, water and soil conservation, and water resource management in the Loess Plateau.

\section{Study Area, Materials and Methods}

\subsection{Experimental Site}

The Nanxiaohegou watershed $\left(107^{\circ} 30^{\prime} \mathrm{E}-107^{\circ} 37^{\prime} \mathrm{E}, 37^{\circ} 41^{\prime} \mathrm{N}-35^{\circ} 44^{\prime} \mathrm{N}\right)$ is located in the hinterland of Dongzhiyuan Loess Platform in the Xifeng District of Qingyang City, Gansu Province, China, which is a sub-basin of the Jinghe River (Figure 1). Its total area is about $36.3 \mathrm{~km}^{2}$, with an altitude between 1050 and $1223 \mathrm{~m}$ above sea level and gully density at $2.68 \mathrm{~km} / \mathrm{km}^{2}$. It is a typical gully area in the Loess Plateau and it has been listed as the national key soil erosion prevention region with the coarse sediment from the Yellow River. In 1954, the Yellow River Xifeng Soil and Water Conservation Experiment Station established a water and soil conservation test site in the middle of the Nanxiaohegou sub-basin, with a total area of $4.8 \mathrm{~km}^{2}$. This area is located in the zone of mid-latitude continental monsoon climate with four distinct seasons and an average annual precipitation of $552.1 \mathrm{~mm}$. However, the precipitation is not evenly distributed throughout the year. The precipitation from July to September accounts for $63.0 \%$ of the annual precipitation. Additionally, the annual precipitation can vary between abundant, normal, or scarce from year to year. The annual average temperature is $9.3^{\circ} \mathrm{C}$ and the annual accumulated temperature is 2700 to $3300{ }^{\circ} \mathrm{C}$. The annual average potential evaporation of this area is $883.4 \mathrm{~mm}$ and the aridity index (the ratio of potential evaporation to precipitation in a given period) is 1.6, with drought being the primary natural disaster. This basin belongs to the temperate forest-steppe zone with no natural forest. However, P. tabulaeformis, R. pseudoacacia, and P. orientalis (the location shown in Figure 1) have been used to create planted forests in this area. 


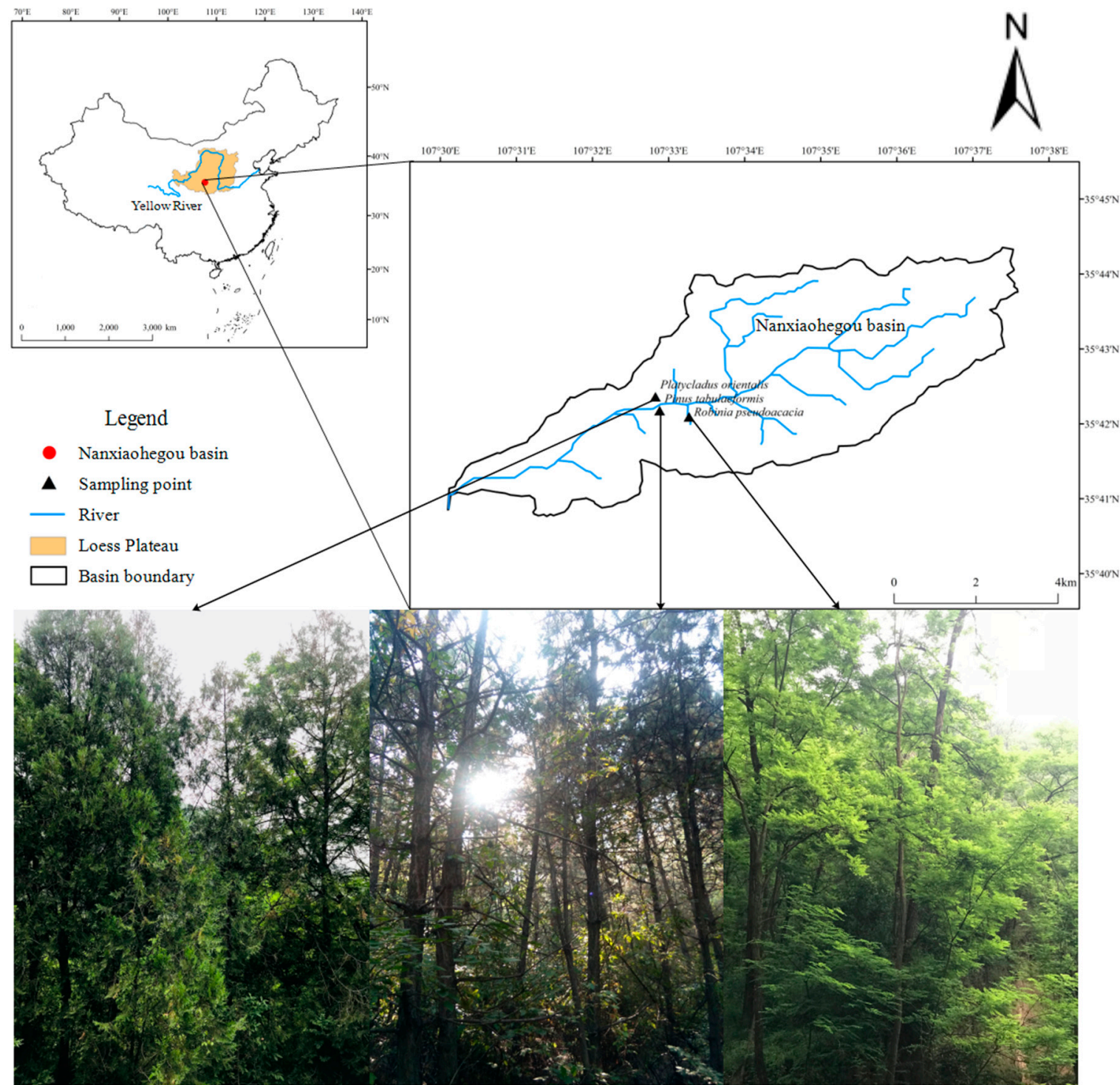

Figure 1. Location of Nanxiaohegou sub-basin in China; inset shows the location of three types of planted forests.

\subsection{Experimental Design}

Field observations were carried out during the growing season (from May to September) between 2015 and 2017 in the Nanxiaohegou Soil and Water Conservation Experiment Station. When considering the factors of landform, slope position, vegetation type, tree age, and the operability of experimental scheme, three types of planted forests (R. pseudoacacia, P. orientalis, and P. tabulaeformis) were selected for soil evaporation and plant interception field observations. Basic information about the experimental plots is shown in Table 1.

Measurement of soil evaporation: Monitoring was performed with a micro vapor analyzer manufactured by Xi'an University of Technology (Xi'an, China) in the selected plots. A hand-made PVC pipe (diameter: $20 \mathrm{~cm}$, length: $30 \mathrm{~cm}$ ) was inserted into the soil with its upper end at the same level as the soil surface. The integrity of the soil surface was maintained during this process. Subsequently, the PVC pipe with the undisturbed soil column was removed. The base of the pipe was covered with a double layer of gauze to prevent the soil in the PVC pipe from dropping out, which could have affected the accuracy of the test. An electronic balance with an accuracy of $0.01 \mathrm{~g}$ was used to weigh the sampled soil. The interval between the tests was $3 \mathrm{~d}$. All of the tests were completed within $1 \mathrm{~h}$ to ensure the reliability 
of the measured values. Soil evaporation (g) was taken as the difference between two measurements, which could be calculated the volume of soil evaporation $\left(\mathrm{cm}^{3}\right)$ by density formula and then converted to depth $(\mathrm{mm})$ by taking into account the diameter of the PVC tube. Three parallel tests were performed in the adjacent sites of each plot during the entire monitoring process. After each rainfall, the soil column in the PVC test tube was replaced and then re-weighed to obtain a new benchmark. For each plot, the average value of the results from three parallel tests was taken as the soil evaporation during a known period of time.

Table 1. Basic information about the experimental plots ${ }^{\mathrm{a}}$.

\begin{tabular}{|c|c|c|c|c|c|c|c|c|c|c|}
\hline Vegetation & $\begin{array}{c}\text { Soil } \\
\text { Texture }\end{array}$ & $\begin{array}{c}D \\
(\mathrm{~m})\end{array}$ & $\begin{array}{c}\rho \\
\left(\text { Plants km }{ }^{-2}\right)\end{array}$ & $\begin{array}{l}\text { VFC } \\
(\%)\end{array}$ & $\begin{array}{c}\Phi \\
(\mathrm{cm})\end{array}$ & $\begin{array}{c}W \\
(\mathrm{~cm})\end{array}$ & $\begin{array}{c}h \\
(\mathrm{~cm})\end{array}$ & $\begin{array}{c}\gamma_{d} \\
\left(\mathrm{~g} \mathrm{~cm}^{-3}\right)\end{array}$ & $\begin{array}{l}f c \\
(\%)\end{array}$ & $\begin{array}{l}s \\
\left(^{\circ}\right)\end{array}$ \\
\hline $\begin{array}{c}\text { Robinia } \\
\text { pseudoacacia }\end{array}$ & Silt loam & 50-100 & 200,000 & 85 & 19.1 & 138.8 & 416.2 & 1.45 & 18.82 & 22.20 \\
\hline $\begin{array}{l}\text { Platycladus } \\
\text { orientalis }\end{array}$ & Silt loam & 50-100 & 160,000 & 75 & 34.0 & 198.4 & 602.4 & 1.25 & 20.40 & 23.17 \\
\hline $\begin{array}{l}\text { Pinus } \\
\text { tabulaeformis }\end{array}$ & Silt loam & 50-100 & 170,000 & 80 & 57.3 & 239.5 & 693.3 & 1.29 & 22.00 & 19.30 \\
\hline
\end{tabular}

Measurement of plant interception: Plant interception includes canopy and trunk interception. In each plot, five representative trees were selected with similar height and growth. Eight rain measure cylinders (diameter: $20 \mathrm{~cm}$; depth: $20 \mathrm{~cm}$ ) were evenly placed at eight different positions around each representative tree. Data collected from the cylinders were recorded in time after each rainfall. The average value of rainfall measured by the cylinders was taken as the throughfall in the forest. The difference between precipitation and throughfall was used to calculate the canopy interception. Polyethylene plastic tubes were used to monitor trunk interception, which were screwed into the trunk in an S-shape. Silicone sealant was used to tightly secure the plastic tube against the trunk to prevent raindrops from leaking out. All of the monitoring data were collected within $1 \mathrm{~h}$ after rainfall in order to ensure the accuracy of plant interception data and to avoid the influence of evaporation.

Measurement of soil water content: A TRIME-PICO system with Time Domain Reflectrometry (TDR) tube access probes (IMKO, Ettlingen, Germany) was used to measure the volumetric soil moisture. In each plot, three TDR tube access probes were placed at points 0.7 times the average radius of the canopy. Subsequently, the handheld sensors (IMKO, Ettlingen, Germany) were used to measurement the volumetric soil moisture of the three forests during the growing season. The interval between the tests was $3 \mathrm{~d}$. Additional tests were performed after rainfall. The test depth was set to $2.2 \mathrm{~m}$ with the vertical spacing between the test points at $10 \mathrm{~cm}$ from the depth of 0 to $100 \mathrm{~cm}$ and at $20 \mathrm{~cm}$ from the depth of $100 \mathrm{~cm}$ to $220 \mathrm{~cm}$. To ensure the reliability of the measured values, all of the tests were completed within $1 \mathrm{~h}$.

Measurement of soil bulk density: A soil pit of $1 \mathrm{~m}$ deep was dug at a flat spot. Afterwards, a steel ring with a volume of $100 \mathrm{~cm}^{3}$ was used to sample the soil at a depth of $10 \mathrm{~cm}, 20 \mathrm{~cm}, 40 \mathrm{~cm}, 60 \mathrm{~cm}$, $80 \mathrm{~cm}$, and $100 \mathrm{~cm}$ by filling the ring with soil without disturbing or loosening the soil. Excessive soil was removed to ensure the surface of the soil and the ring were at the same level. The sampled soil from each layer was put in an aluminium box to calculate the soil water content. An electronic balance with accuracy of $0.01 \mathrm{~g}$ was used to measure the weight of the moist soil from the ring. The soil bulk density was calculated according to the formula:

$$
\gamma=100 M[V(1+W)]
$$

where $\gamma$ is the soil bulk density $\left(\mathrm{g} / \mathrm{cm}^{3}\right) ; M$ is the total mass of the ring and the wet soil $(\mathrm{g}) ; V$ is the volume of the ring $\left(\mathrm{cm}^{3}\right)$; and, $W$ is the soil water content of the corresponding layer $\left(\mathrm{cm}^{3} / \mathrm{cm}^{3}\right)$. 
Three parallel samples were taken from each layer and the soil bulk density of the layer was obtained from the average value of the three samples.

Meteorological data monitoring: Watch Dog series portable weather stations purchased from Spectrum Technologies Inc. (Lincoln, USA) monitored the meteorological data of the plots, including precipitation, temperature, humidity, and wind speed in real time. The monitoring interval was $1 \mathrm{~h}$, and the meteorological data were collected and analyzed on a monthly basis. The distance between the weather station and the furthest plot was no more than $100 \mathrm{~m}$.

\subsection{Research Methods}

\subsubsection{Water Balance Approach}

Rainfall is the only source of green water in the studied area, which can be categorized into blue water and green water according to its destination. Blue water is the precipitation that flows over the land surface; i.e., runoff water. Green water is from precipitation, but it refers to precipitation that is used by plants via transpiration. The water balance approach is a traditional method for determining green water flux. Based on the principle of water balance, the green water resource of a region can be derived from the difference between water recharge and consumption. The gully region of the Loess Plateau, which was the study area, has a very deep underground water level. Therefore, the underground water recharge is negligible and surface runoff that is caused by precipitation can be regarded as the amount of blue water. For a closed area, the water balance equation is:

$$
P=W_{b}+W_{g}=\alpha P+W_{g}
$$

Thus, green water can be estimated by the following equation:

$$
W_{g}=(1-\alpha) P
$$

where $P$ is precipitation $(\mathrm{mm}) ; W_{b}$ is the amount of blue water resources $(\mathrm{mm}) ; W_{g}$ is the amount of green water resources $(\mathrm{mm})$; and, $\alpha$ is the runoff coefficient. Green water resources include two parts, the green water flux and green water storage. Green water flux is the actual evapotranspiration, which consists of plant transpiration, soil evaporation, and plant interception. Soil evaporation and plant interception are not used directly by plants, which are classified as non-productive green water. Plant transpiration is classified as productive green water. Green water storage is the variation in soil water storage. Over twenty years, the soil water storage variation is approximately 0 , but it cannot be ignored under a monthly timescale. The amount of green water resources can be calculated, as follows:

$$
W_{g}=E+I+T+\Delta W
$$

where $E$ is soil evaporation (mm); $I$ is plant interception (mm); $T$ is plant transpiration (mm); and, $\Delta W$ is the variation in soil water storage $(\mathrm{mm})$. Of these, soil evaporation and plant interception were obtained from experimental measurements. Soil water storage is one of the indicators for measuring the amount of soil water resources. It refers to the volume of water that is contained in the soil above a certain depth per unit area, which can potentially be used by vegetation. Its calculation is as follows:

$$
\begin{gathered}
W_{i}=w_{i} r_{i} h_{i} \\
W=\sum W_{i}
\end{gathered}
$$

where $W$ is soil water storage $(\mathrm{mm}) ; W_{i}$ is the soil water storage of the layer $i(\mathrm{~mm}) ; w_{i}$ is the soil water content of the layer $i\left(\mathrm{~cm}^{3} / \mathrm{cm}^{3}\right) ; r_{i}$ is the dry bulk density of the layer $i$ of the soil, $\left(\mathrm{g} / \mathrm{cm}^{3}\right)$; and, $h_{i}$ is the thickness of the layer $i(\mathrm{~cm})$. 
A combination of the water balance approach and three typical artificial forests field monitoring, which included soil water content, soil evaporation, and plant interception, was used to calculated green water storage, green water flux, productive green water, and non-productive green water. Thus, the research realized green water separation on a monthly timescale.

\subsubsection{Dual Crop Coefficient Approach}

The crop coefficient method that was recommended by the FAO comprehensively considers the effects of meteorological factors, soil factors, crop types, and growing conditions on green water, and it can be used to simulate the green water consumption process, including vegetation transpiration and soil evaporation. The dual crop coefficient approach is widely used for evaluating field crops evapotranspiration. However, some scholars [17-19] used the approach to simulate forest vegetation transpiration and soil evaporation, including caragana, olive, peach, etc. This study used the dual crop coefficient method that was recommended by FAO-56. The calculation formula is:

$$
E T_{a}=\left(K_{c b}+K_{e}\right) E T_{0}
$$

where $E T_{a}$ is the actual green water consumption, i.e., the actual evapotranspiration (mm); $K_{c b}$ is the basal crop coefficient; $K_{e}$ is the soil evaporation coefficient; and, $E T_{0}$ is the potential green water consumption (mm). The calculation of $E T_{0}$ used the FAO recommended Penman-Monteith approach [16] with the energy balance method and vapor diffusion theory as the basis. The following formula is used for the calculation:

$$
E T_{0}=\frac{0.408 \Delta\left(R_{n}-G\right)+\gamma \frac{900}{T+273} U_{2}\left(e_{a}-e_{d}\right)}{\Delta+\gamma\left(1+0.34 U_{2}\right)}
$$

where $\Delta$ is the tangent slope of the saturated vapor pressure versus temperature curve at the temperate of $T\left(\mathrm{kPa} \cdot{ }^{\circ} \mathrm{C}^{-1}\right) ; R_{n}$ is the net radiation of the canopy surface $\left(\mathrm{MJ} \cdot \mathrm{m}^{-2} \cdot \mathrm{d}^{-1}\right) ; G$ is the heat flux of the soil $\left(\mathrm{MJ} \cdot \mathrm{m}^{-2} \cdot \mathrm{d}^{-1}\right) ; \gamma$ is the psychrometric constant $\left(\mathrm{kPa} \cdot{ }^{\circ} \mathrm{C}^{-1}\right) ; \mathrm{T}$ is the average temperature $\left({ }^{\circ} \mathrm{C}\right)$; $U_{2}$ is the average wind speed at $2 \mathrm{~m}$ height $\left(\mathrm{m} \cdot \mathrm{s}^{-1}\right) ; e_{a}$ is the actual water vapor pressure $(\mathrm{kPa})$; and, $e_{d}$ is the saturated water vapor pressure $(\mathrm{kPa})$. Of these, $\Delta, R_{n}, G$, and $U_{2}$ can be calculated with the observation data from meteorological stations.

\subsubsection{Complementary Relationship-Based Model}

Utilizing an analysis based on energy balance, Bouchet [14] proposed a theory that potential evapotranspiration $\left(E T_{p}\right)$ and actual evapotranspiration $\left(E T_{a}\right)$ are strongly coupled through land-atmosphere feedbacks at large homogeneous surfaces, with minimal advection of heat and moisture. The relationship has come to be known as the complementary relationship between $E T_{a}$ and $E T_{p}$. When the moisture at the surface is sufficient, $E T_{a}$ is equal to $E T_{p}$, which is the wet-environment evapotranspiration $E T_{w}$. If the soil moisture is reduced, then $E T_{a}$ will decline; thus, the energy that is used for evapotranspiration will become excessive. If there is no advection, then the energy will remain unchanged when evapotranspiration is reduced. Meanwhile, the reduced $E T_{a}$ will change the temperature and humidity in the area, so the remaining energy will increase $E T_{p}$. The increase of $E T_{p}$ should be equal to the remaining energy. Figure 2 shows the schematic representation of the complementary relationship in regional evapotranspiration. The following equation indicates the relationship between $E T_{a}$ and $E T_{p}$ :

$$
E T_{p}+E T_{a}=2 E T_{w}
$$




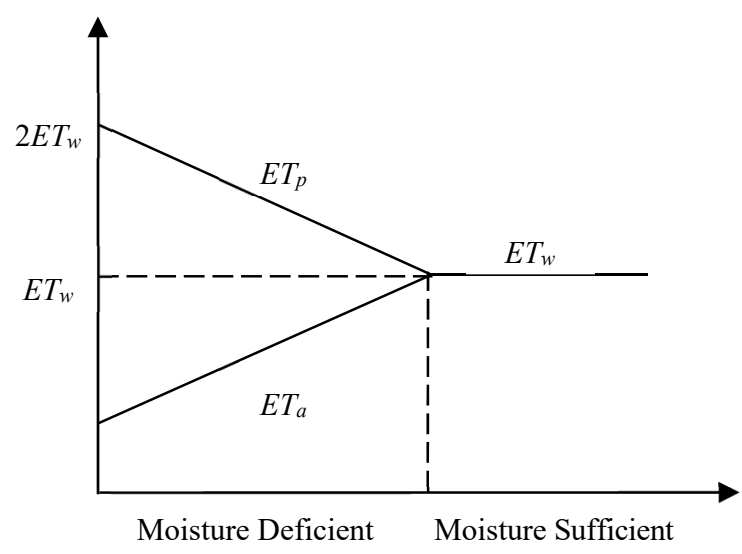

Figure 2. Schematic representation of the complementary relationship in regional evapotranspiration.

\section{- CRAE (Complementary Relationship Areal Evapotranspiration) model}

Morton [20] proposed the CRAE model that is based on complementary relationship theory by introducing the concept of equilibrium temperature. According to this model, for a wet land surface, the evaporation that is derived from the energy balance equation should be equivalent to that derived from the vapor transport equation. By combining the energy balance equation and vapor transport equation, the $E T_{p}$ can be derived:

$$
E T_{p}=\left(R_{n}-G\right)-\lambda_{p} f_{T}\left(T_{p}-T\right)=f_{T}\left(e_{p}-e_{d}\right)
$$

where $\lambda_{p}$ is the thermal conductivity coefficient at the equilibrium temperature; $f_{T}$ is the vapor transport coefficient; $T_{p}$ is the equilibrium temperature $\left({ }^{\circ} \mathrm{C}\right) ; e_{p}$ is the saturated vapor pressure at the equilibrium temperature $(\mathrm{kPa})$; and, other parameters are the same as above. An iteration procedure that is based on Equation (10) can be used to calculate the saturated vapor pressure $e_{p}$ at the equilibrium temperature. Moreover, Morton proposed a formula for calculating the $E T_{w}$ :

$$
E T_{w}=b_{1}+b_{2}\left((1+\gamma p) / \Delta_{p}\right)^{-1}\left(R_{n}-G\right)_{T_{p}}
$$

where $p$ the is atmospheric pressure $(\mathrm{kPa}) ;\left(R_{n}-G\right)_{T p}$ is the available energy at $T_{p} ; \Delta_{p}$ is the slope of the saturated vapor pressure curve at $T_{p}$; and, $b_{1}$ and $b_{2}$ are empirical coefficients. According to relevant research [20], $b_{1}$ is $14 \mathrm{~W} / \mathrm{m}^{2}$ and $b_{2}$ is 1.2. Using $E T_{p}$ and $E T_{w}$ that were derived from the above equations, the actual evapotranspiration $E T_{a}$ can be obtained through Equation (9), which will be:

$$
E T_{a}=2\left\{b_{1}+b_{2}\left((1+\gamma p) / \Delta_{p}\right)^{-1}\left(R_{n}-G\right)_{T_{p}}\right\}-\left\{\left(R_{n}-G\right)-\lambda_{p} f_{T}\left(T_{p}-T\right)\right\}
$$

- AA (advection-aridity) model

Brutsaert and Strier [21] believe that the wet environment can be calculated with the Priestley-Taylor formula, and the potential evapotranspiration can be calculated with the Penman formula. Thus, the AA model was proposed:

$$
E T_{a}=2 \alpha \frac{\Delta}{\Delta+\gamma}\left(R_{n}-G\right)-\left[\frac{\Delta}{\Delta+\gamma}\left(R_{n}-G\right)+\frac{\Delta}{\Delta+\gamma} E_{a}\right]
$$

where $\alpha$ is the empirical coefficient. Priestley and Taylor analyzed the observation data of the large-scale saturated land surface and suggested that $\alpha$ should be 1.26. $E_{a}$ is the air drying force:

$$
E_{a}=\frac{\rho_{a} c_{a}\left(e_{d}-e_{a}\right)}{\gamma r_{a}}
$$


where $\rho_{a}$ is the air density; $c_{a}$ is the constant pressure ratio of the air and $r_{a}$ is the aerodynamic resistance.

- Granger model

Granger [22] derives the quantitative complementary relationship between actual evapotranspiration and potential evapotranspiration through Dalton's evaporation law. By introducing the concept of relative evapotranspiration, the equation for estimating the actual evapotranspiration, $E T_{a}$, is created:

$$
E T_{a}=\left(\frac{\Delta}{\gamma} R\left(R_{n}-G\right)+R E_{a}\right) /\left(\frac{\Delta}{\gamma} R+1\right)
$$

where $R$ is the relative evapotranspiration. Its relationship with relative drying force $D$ is shown, as follows:

$$
R=\frac{1}{1+a_{2} \exp \left(a_{1} D\right)}
$$

where $a_{1}$ and $a_{2}$ are empirical coefficients, which are 8.045 and 0.028 , respectively, according to Granger's observation data of the underlying surfaces.

\subsubsection{Model Evaluation}

In this study, the green water flux that was obtained by the water balance approach is used as the reference value. The consistency coefficient $(d)$, Nash-Sutcliffe coefficient $\left(C_{D}\right)$, root mean square error (RMSE), and normalized root mean square error (NRMSE) were used to evaluate the applicability and accuracy of the three complementary relationship-based models in simulating the green water fluxes of different types of vegetation in the Nanxiaohegou sub-basin during the growing season between 2015 and 2017. The formulas are as follows:

$$
\begin{gathered}
d=1-\frac{\sum_{i=1}^{n}\left(X_{i}-Y_{i}\right)^{2}}{\sum_{i=1}^{n}\left(\left|Y_{i}-\bar{X}\right|+\left|X_{i}-\bar{X}\right|\right)^{2}} \\
C_{D}=1-\frac{\sum_{i=1}^{n}\left(Y_{i}-X_{i}\right)^{2}}{\sum_{i=1}^{n}\left(X_{i}-\bar{X}\right)^{2}} \\
\text { RMSE }=\sqrt{\frac{1}{n} \sum_{i=1}^{n}\left(Y_{i}-X_{i}\right)^{2}} \\
\text { NRMSE }=\frac{R M S E}{X_{\max }-X_{\min }}
\end{gathered}
$$

where $n$ is the number of samples; $X_{i}$ is the green water flux obtained by the water balance approach; $Y_{i}$ is the simulated value based on the model to be evaluated; $\bar{X}$ is the average value of $X_{i} ; X_{\max }$ is the maximum value of $X_{i}$; and, $X_{\min }$ is the minimum value of $X_{i}$.

\section{Results}

\subsection{Green Water Separation Based on the Water Balance Approach}

The field monitoring data collected between 2015 and 2017 from the Nanxiaohegou sub-basin during the growing season (May to September), including soil evaporation $(E)$, plant interception $(I)$, and soil water content $(W)$, were used to calculate the green water fluxes of three typical types of planted forests and achieve green water separation based on the water balance equation of a closed area; the results are presented in Figure 3. Figure 3 shows that the interannual variability in the total amount of green water during the growing season was low for all three experimental plots. As green water 
comes from precipitation, the change in the monthly green water was consistent with the change of monthly precipitation. Thus, the monthly green water increases from May to July and it decreases from August to September, as shown in Figure 3. The maximum monthly value during the studied period occurred in August 2017, with the green water fluxes for the forests of R. pseudoacacia, P. orientalis, and P. tabulaeformis at $172.0 \mathrm{~mm}, 167.3 \mathrm{~mm}$, and $165.7 \mathrm{~mm}$, respectively. However, when compared to the total amount of green water, the monthly productive green water component changes in an inverted "V" shape with the month. In May and June, plants grow rapidly and the leaf area index increases, which result in a high level of transpiration. Although the precipitation increases from May to June, it cannot meet the requirement of the plants for water. Therefore, plants have to absorb a considerable amount of water from the soil to maintain their growth, causing negative green water storage. In July and August (the middle stage of the growing season), plants need the most nutrients and plant transpiration is the highest, due to high sunshine intensity, high temperature, and low air humidity. In September, plant growth starts to decline, and thus plant transpiration decreases. Non-productive green water changes in a "V" shape, which means that plant interception and soil evaporation drops first and then increases. In July and August, the increased precipitation in the studied area, combined with other factors, such as solar radiation, air temperature, soil temperature, humidity, and wind speed, leads to higher air humidity, thereby resulting in lower soil water evaporation. In September, the combination of decreased precipitation, lower air humidity, and higher wind speed contributes to higher soil evaporation. Therefore, the evaporation drops first and then increases. Green water storage is the variation in soil water storage. The green water that is stored in the forests of R. pseudoacacia and $P$. orientalis was mostly negative during the study period, demonstrating greater soil water extraction than recharge. By contrast, the amount of green water that was stored by the $P$. tabulaeformis forest was large, which means that the soil water extraction was relatively small and the soil water content was relatively stable.

In August 2017, the precipitation in the studied area was $215 \mathrm{~mm}$ and this value dropped to only $14.7 \mathrm{~mm}$ in September. The significant variation in monthly precipitation resulted in the inability of the soil to store water over a short time and most of the precipitation became blue water. During this period, green water storage changed significantly. Therefore, it can be concluded that, when the amount of precipitation was high, the soil was unable to store more water and the amount of green water storage did not significantly increase. However, under conditions of very little precipitation, the ongoing consumption of green water storage due to plant transpiration and soil evaporation resulted in negative storage of green water in the three planted forests in September 2017, which was significantly different from the green water storage during the same period in 2015 and 2016. In summary, the significant variation in precipitation within a short period was detrimental to green water storage and it exacerbated soil erosion in the studied area. Additionally, the variation in productive green water that was caused by the rapid change in precipitation differed between the three planted forests, with the lowest variation in productive green water occurring in the R. pseudoacacia forest. This finding indicates that the change in meteorological conditions had the smallest impact on the transpiration of R. pseudoacacia forest in the studied area. 


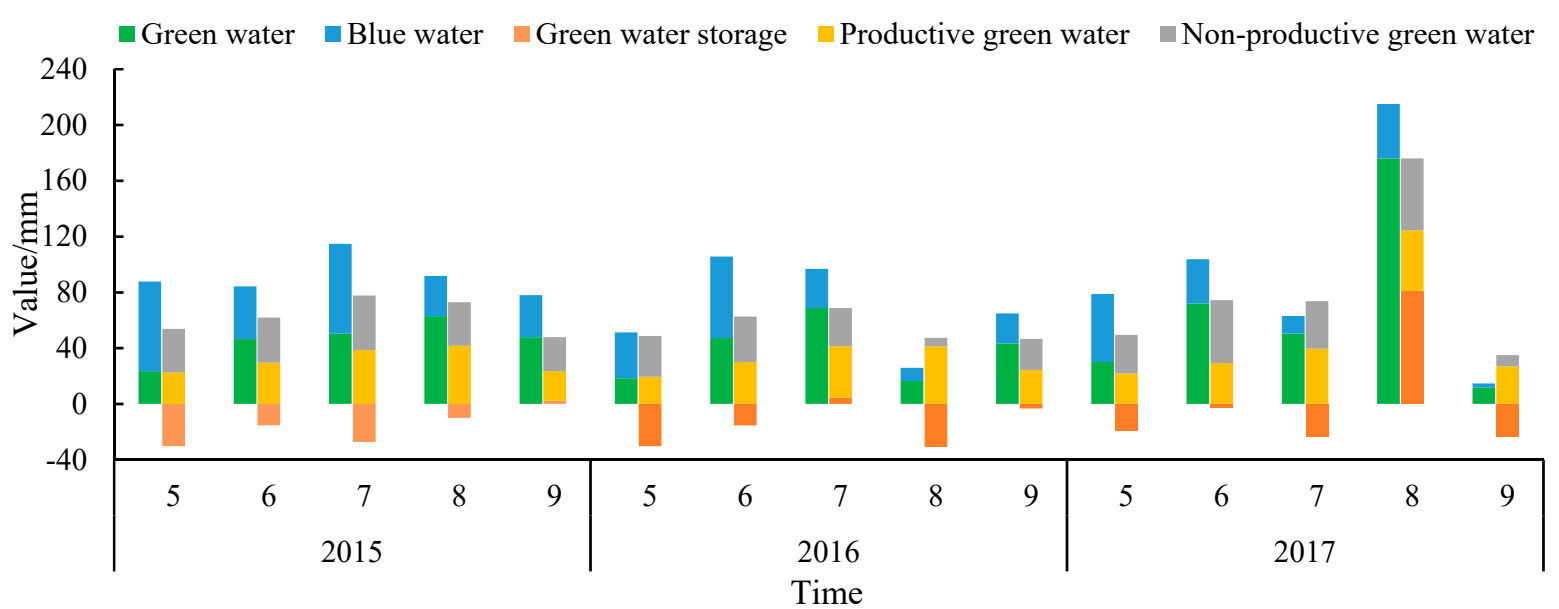

(a)

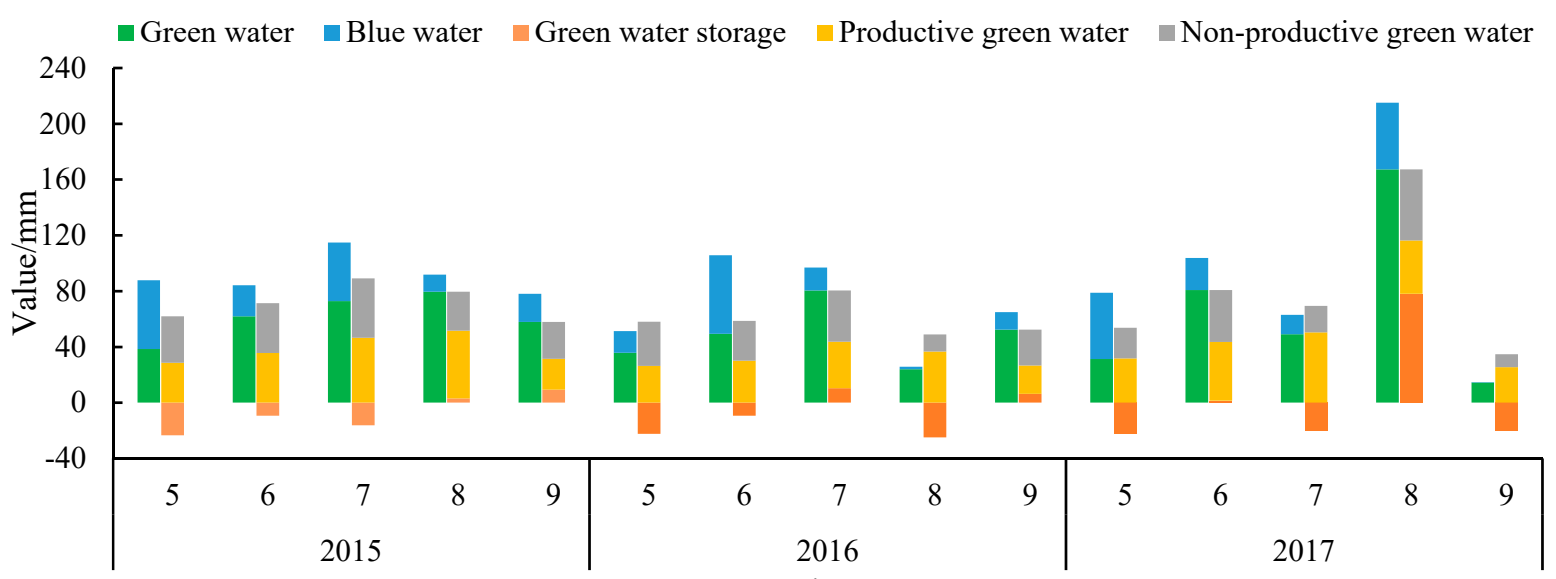

(b)

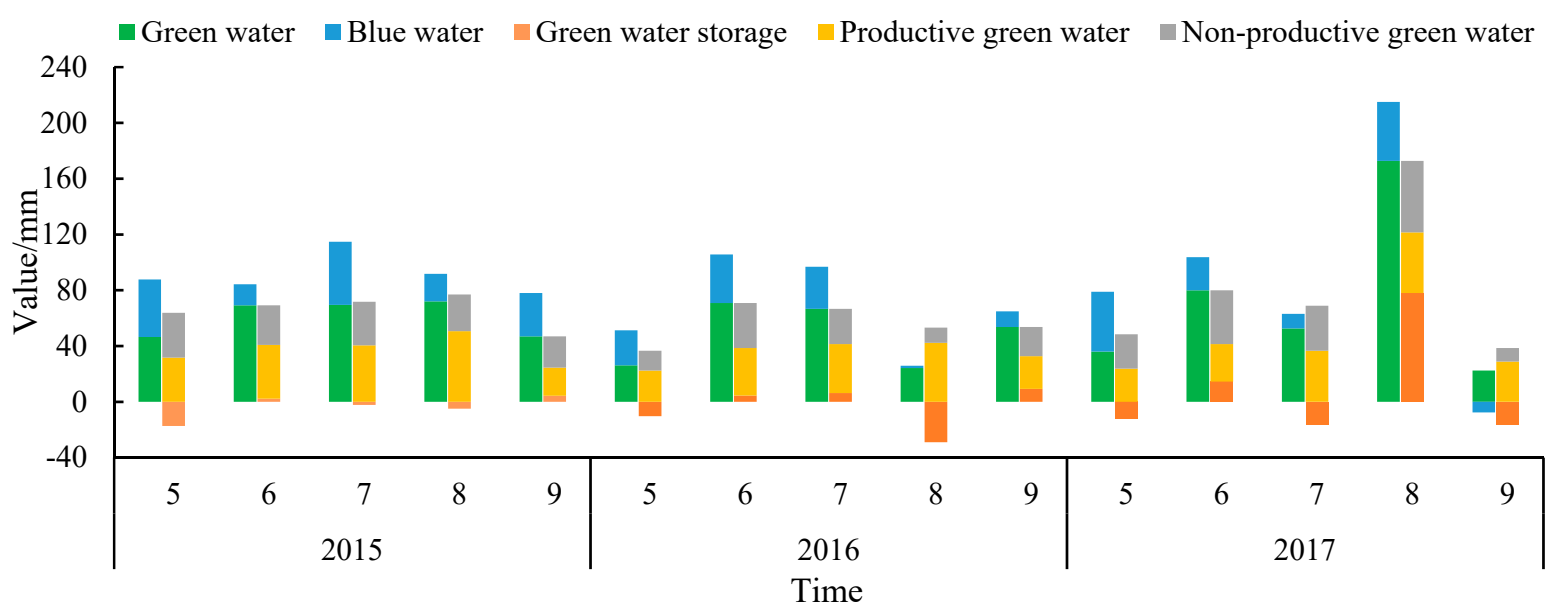

(c)

Figure 3. Fluctuations in green water of (a) Robinia pseudoacacia, (b) Platycladus orientalis, and (c) Pinus tabulaeformis during the growing season 2015-2017.

\subsection{Changes of Crop Coefficients in Different Planted Forests}

This study used the results of green water separation, based on the water balance equation, combined with the dual crop coefficient method and the Penman-Monteith formula, to obtain the 
$K_{c b}, K_{e}$, and $K_{c}$ of the three forests in each month during the growing season. The results are shown in Table 2. The results show that the temporal change of $K_{c b}$ greatly differed from that of $K_{e}$ during the growing season between 2015 and 2017. Driven by plant growth and the favorable meteorological conditions, $K_{c b}$, which reflects the vegetation transpiration, increased from a low value in the early part of the growing season to its maximum value in the middle part of the growing season. During the decline stage of the growing season, $K_{c b}$ decreased with the drop of the leaf area index of the canopy and vegetation coverage. In addition, $K_{e}$, which is used to reflect soil evaporation, was large at the start of the growing season. However, with continuing growth of the forest, the canopy coverage increased and the available moisture in the soil decreased, which restricted soil evaporation; thereby, $K_{e}$ dropped. In the middle stage of the growing season, after the recharge of soil water, $K_{e}$ first increased before it started to drop again, as more soil moisture was consumed. In the final stage of the growing season, the combination of soil moisture and crop growth conditions contributed to the increase in $K_{e}$. However, soil moisture was very high in August 2017 because of continuous heavy rainfall, and $K_{e}$ increased significantly in the final stage of the growing season. Therefore, the peak values of $K_{e}$ for the forests of R. pseudoacacia, P. orientalis, and P. tabulaeformis all occurred in the final stage of the growing season, which were $0.75,0.53$, and 0.55 , respectively. The index $K_{c}$ was influenced by both $K_{e}$ and $K_{c b}$, which reveals the change in actual green water flux with local meteorological factors, and the conditions of plant growth and soil moisture. Therefore, $K_{c}$ increased at the beginning of the growing season, and it remained at a high level during the middle stage, before it started to decline in the final stage of the growing season. From the above comparisons, it can be concluded that $R$. pseudoacacia has the largest crop index, followed by the forests of $P$. orientalis and $P$. tabulaeformis.

Table 2. Temporal crop coefficient change for different types of vegetation during the growing season between 2015 and 2017.

\begin{tabular}{|c|c|c|c|c|c|c|c|c|c|c|}
\hline \multirow{2}{*}{ Year } & \multirow{2}{*}{ Month } & \multicolumn{3}{|c|}{ Robinia pseudoacacia } & \multicolumn{3}{|c|}{ Platycladus orientalis } & \multicolumn{3}{|c|}{ Pinus tabulaeformis } \\
\hline & & $K_{c b}$ & $K_{e}$ & $K_{c}$ & $K_{c b}$ & $K_{e}$ & $K_{c}$ & $K_{c b}$ & $K_{e}$ & $K_{c}$ \\
\hline \multirow{6}{*}{2015} & 5 & 0.56 & 0.47 & 1.03 & 0.26 & 0.50 & 0.76 & 0.17 & 0.44 & 0.61 \\
\hline & 6 & 0.59 & 0.56 & 1.15 & 0.62 & 0.25 & 0.87 & 0.19 & 0.45 & 0.64 \\
\hline & 7 & 0.76 & 0.41 & 1.17 & 0.68 & 0.29 & 0.97 & 0.35 & 0.31 & 0.66 \\
\hline & 8 & 0.79 & 0.41 & 1.20 & 0.58 & 0.45 & 1.03 & 0.57 & 0.25 & 0.82 \\
\hline & 9 & 0.60 & 0.52 & 1.12 & 0.21 & 0.60 & 0.82 & 0.25 & 0.47 & 0.73 \\
\hline & $\begin{array}{c}\text { Growing } \\
\text { season }\end{array}$ & 0.66 & 0.47 & 1.13 & 0.47 & 0.42 & 0.89 & 0.31 & 0.38 & 0.69 \\
\hline \multirow{6}{*}{2016} & 5 & 0.45 & 0.39 & 0.84 & 0.15 & 0.50 & 0.65 & 0.09 & 0.49 & 0.58 \\
\hline & 6 & 0.45 & 0.44 & 0.89 & 0.34 & 0.42 & 0.76 & 0.15 & 0.44 & 0.59 \\
\hline & 7 & 0.71 & 0.37 & 1.07 & 0.42 & 0.36 & 0.78 & 0.36 & 0.28 & 0.64 \\
\hline & 8 & 0.80 & 0.31 & 1.11 & 0.52 & 0.37 & 0.89 & 0.35 & 0.30 & 0.65 \\
\hline & 9 & 0.45 & 0.50 & 0.95 & 0.26 & 0.52 & 0.78 & 0.22 & 0.35 & 0.57 \\
\hline & $\begin{array}{c}\text { Growing } \\
\text { season }\end{array}$ & 0.57 & 0.40 & 0.97 & 0.34 & 0.43 & 0.77 & 0.23 & 0.37 & 0.61 \\
\hline \multirow{6}{*}{2017} & 5 & 0.42 & 0.40 & 0.82 & 0.20 & 0.41 & 0.61 & 0.14 & 0.34 & 0.48 \\
\hline & 6 & 0.59 & 0.35 & 0.94 & 0.41 & 0.35 & 0.84 & 0.25 & 0.35 & 0.60 \\
\hline & 7 & 0.57 & 0.44 & 1.01 & 0.52 & 0.34 & 0.86 & 0.39 & 0.30 & 0.69 \\
\hline & 8 & 0.62 & 0.75 & 1.38 & 0.82 & 0.53 & 1.35 & 0.77 & 0.55 & 1.32 \\
\hline & 9 & 0.65 & 0.35 & 1.01 & 0.28 & 0.43 & 0.71 & 0.38 & 0.12 & 0.51 \\
\hline & $\begin{array}{c}\text { Growing } \\
\text { season }\end{array}$ & 0.57 & 0.46 & 1.03 & 0.45 & 0.41 & 0.87 & 0.39 & 0.33 & 0.72 \\
\hline
\end{tabular}

\subsection{Applicability Evaluation of Complementary Relationship-Based Models}

Based on the daily meteorological data during the growing season (May to September) between 2015 and 2017, these three complementary relationship-based models were used to simulate the green water flux on a weekly basis. The diagram (Figures 4-6) of green water fluxes for the three forests was 
created using the water balance approach and by the application of the scattered simulation results of complementary relationship-based models in order to evaluate the applicability of these three models in the studied area. The average weekly green water fluxes for the forests of R. pseudoacacia, P. orientalis, and P. tabulaeformis were $22.53 \mathrm{~mm} / \mathrm{w}, 16.07 \mathrm{~mm} / \mathrm{w}$, and $13.33 \mathrm{~mm} / \mathrm{w}$, respectively. The results of scatter points fitting of the three models were different from those of the measured values. The CRAE model had the best fitting, and the models of AA and Granger showed large simulation errors. The simulation results for the forests of $P$. orientalis and $P$. tabulaeformis were generally higher than the results that were calculated with the water balance approach. This indicates that the applicability of these three models differs for different types of vegetation. The scattered points for R. pseudoacacia, $P$. orientalis, and $P$. tabulaeformis forests that were concentrated at the points of $25 \mathrm{~mm} / \mathrm{w}, 15 \mathrm{~mm} / \mathrm{w}$, and $10 \mathrm{~mm} / \mathrm{w}$, respectively. When the green water flux becomes larger or smaller, the distribution of the scattered points is more dispersed and the model accuracy decreases. The distribution of the scattered points that were obtained from simulation fit well with the mean value of measured green water flux.

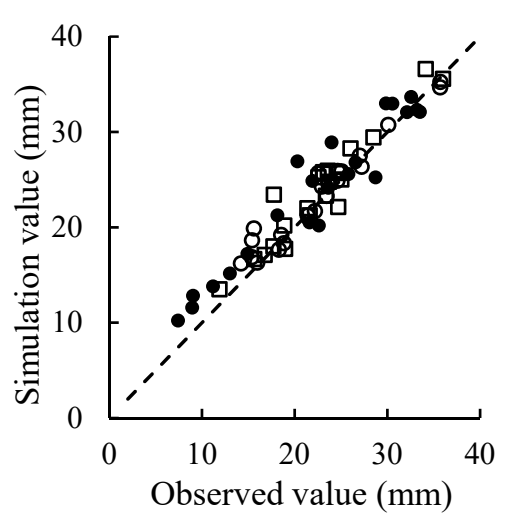

(a)

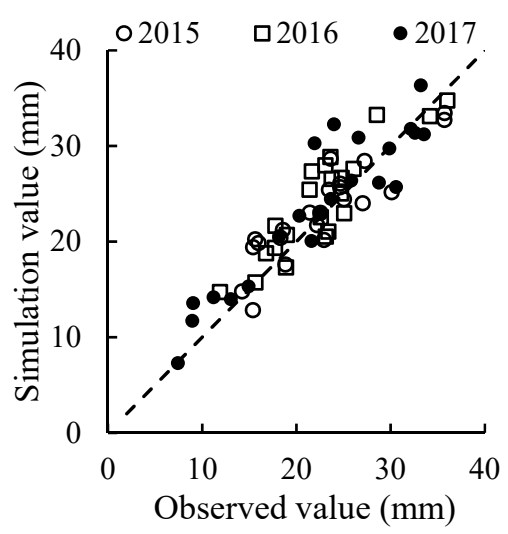

(b)

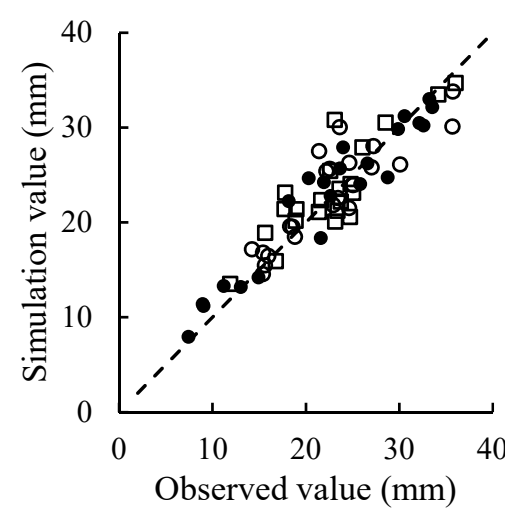

(c)

Figure 4. Scatter plot of green water fluxes derived from (a) complementary relationship areal evapotranspiration (CRAE) model, (b) advection-aridity (AA) model, and (c) Granger model and the water balance approach for Robinia pseudoacacia from 2015 to 2017.

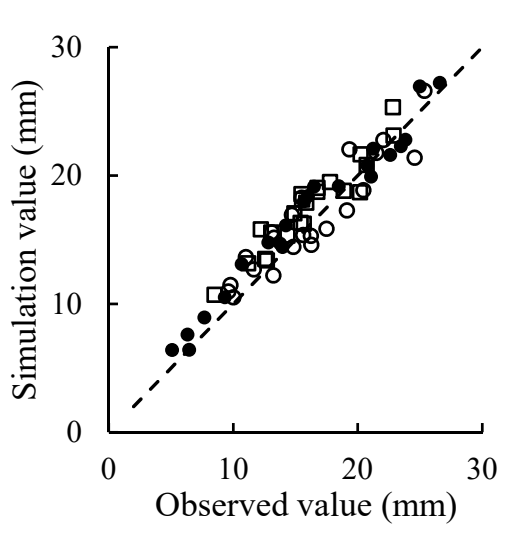

(a)

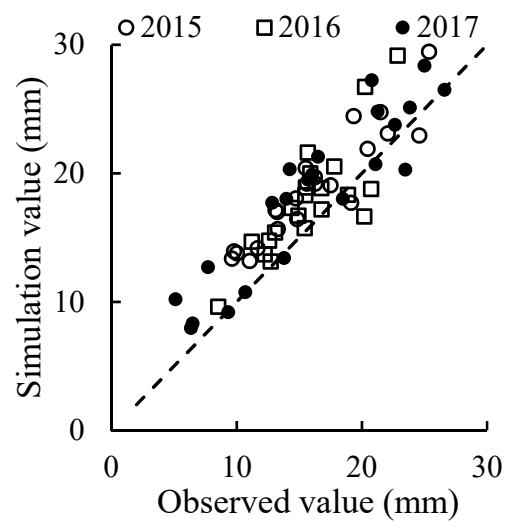

(b)

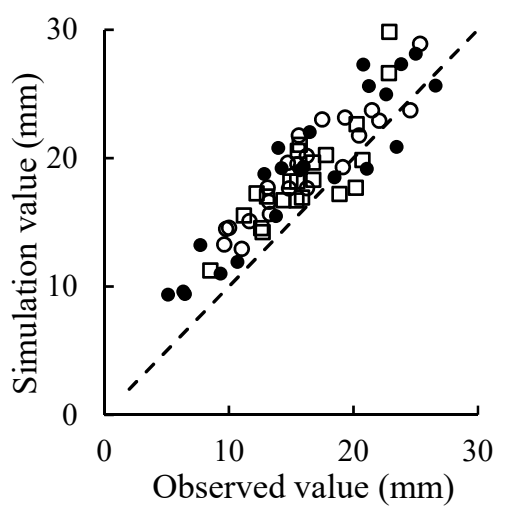

(c)

Figure 5. Scatter plot of green water fluxes derived from (a) CRAE model, (b) AA model, and (c) Granger model and the water balance approach for Platycladus orientalis from 2015 to 2017. 


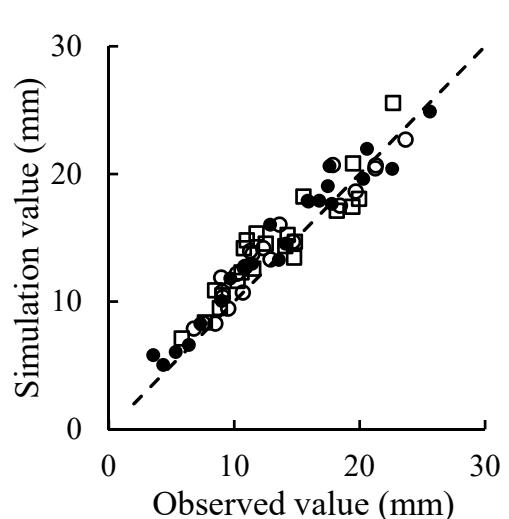

(a)

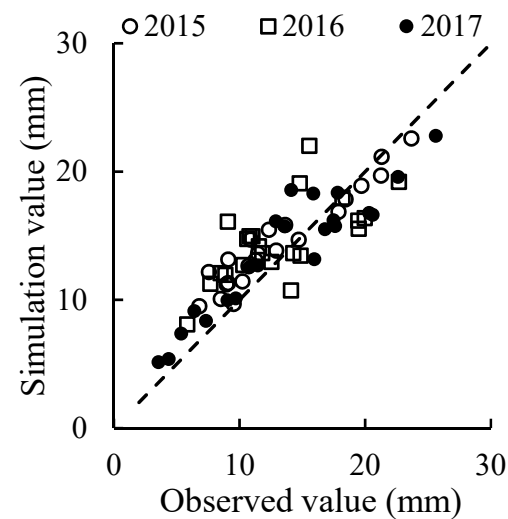

(b)

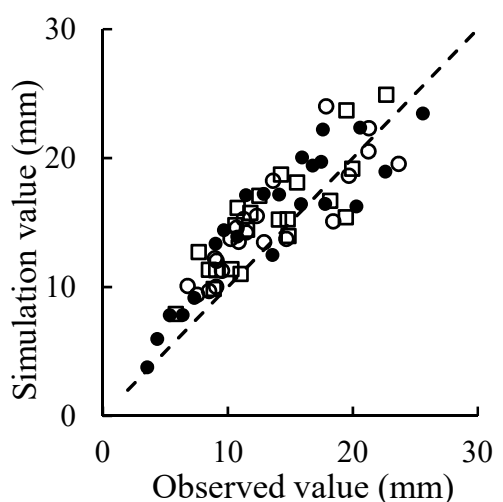

(c)

Figure 6. Scatter plot of green water fluxes derived from (a) CRAE model, (b) AA model, and (c) Granger model and the water balance approach for Pinus tabulaeformis from 2015 to 2017.

In order to evaluate the accuracy of weekly green water fluxes that were derived from the simulation of the complementary relationship-based models in a more reliable way, this paper also analyzed the $d$, $C_{D}, R M S E$, and NRMSE of the simulation results with the values that were calculated by the water balance approach as the standard values, which are shown in Table 3. The values of $d$ and $C_{D}$ reveal the consistency between the two methods, with a larger value representing a higher consistency. A smaller value of RMSE indicates a closer similarity between the two methods. An NRMSE value that is close to 0 represents a small difference between the two methods. It can be seen that the simulation results of the CRAE model matches best with the results that were derived from the water balance approach for the three types of vegetation, with the value of $d$ at 0.97 for the three forests; with the value of $C_{D}$ at $0.89,0.88$, and 0.88; RMSE at $2.19 \mathrm{~mm}, 1.72 \mathrm{~mm}$, and $1.76 \mathrm{~mm}$; and, NRMSE at $9 \%, 8 \%$, and $7 \%$ for the forests of R. pseudoacacia, P. orientalis, and P. tabulaeformis, respectively. These results are consistent with the scatter plots that are shown in Figures 4-6. According to the value of NRMSE, the applicability of the CRAE model is excellent for all three types of forests, while the applicability of the AA and Granger model is classified at a good level. For R. pseudoacaci, the accuracy of Granger is higher than that of the AA model, but it is the opposite for the forests of P. orientalis and P. tabulaeformis.

Table 3. Accuracy of the complementary relationship-based models in simulating green water fluxes for different types of vegetation from 2015 to 2017.

\begin{tabular}{cccccc}
\hline Vegetation & Model & $\boldsymbol{d}$ & $\boldsymbol{C}_{\boldsymbol{D}}$ & RMSE $(\mathbf{m m})$ & NRMSE (\%) \\
\hline \multirow{2}{*}{ Robinia } & CRAE & 0.97 & 0.89 & 2.19 & 9 \\
pseudoacacia & AA & 0.94 & 0.79 & 3.06 & 12 \\
& Granger & 0.95 & 0.84 & 2.70 & 11 \\
\hline \multirow{2}{*}{ Platycladus } & CRAE & 0.97 & 0.88 & 1.72 & 8 \\
orientalis & AA & 0.89 & 0.53 & 3.43 & 16 \\
& Granger & 0.87 & 0.48 & 3.62 & 17 \\
\hline \multirow{2}{*}{ Pinus } & CRAE & 0.97 & 0.88 & 1.76 & 8 \\
tabulaeformis & AA & 0.90 & 0.70 & 2.79 & 13 \\
& Granger & 0.89 & 0.64 & 3.08 & 14 \\
\hline
\end{tabular}

In summary, the CRAE model has the strongest applicability and the highest accuracy for the three planted forests in the Nanxiaohegou sub-basin. CRAE meets the requirement for the simulation of green water flux in the studied area and it can be used as a recommended method for the simplification of green water flux in this area. 


\subsection{Parameter Calibration and Simulation Results Evaluation of the CRAE Model}

Based on the previous analysis, we found that the CRAE model has the best applicability among the three complementary relationship-based models. Therefore, the CRAE model was selected to calibrate its parameters, so that the green water fluxes for the three types of vegetation that were simulated by the model can be more accurate. According to the definition of the CRAE model, $b_{1}$, the advection energy, is the minimum available energy of evapotranspiration in a wet environment. When the net radiation is large, the value of $b_{1}$ is very small. $b_{2}$ is the advection parameter under large scale, whose physical meaning is similar to parameter $\alpha$ in the AA model. The parameters of the CRAE model were adjusted on a weekly timescale by following two principles: one is to ensure the difference between the actual evapotranspiration estimated by the CRAE model and the value calculated by the water balance method is as small as possible; the second principle is to adjust the relevant parameters according to the difference of the net radiation value between different forests. According to the above principles and related literature [23], the model parameters were continually manually adjusted to obtain the optimal parameter values. The optimal values of $b_{1}$ and $b_{2}$ for $R$. pseudoacacia, P. orientalis, and P. tabulaeformis forests were $12.9 \mathrm{~W} / \mathrm{m}^{2}$ and $0.89,11.6 \mathrm{~W} / \mathrm{m}^{2}$ and 1.16 , and $12.2 \mathrm{~W} / \mathrm{m}^{2}$ and 0.91 , respectively.

The actual green water fluxes of the three forests were simulated by the CRAE model with calibrated parameters. The results are shown in Figure 7 and Table 4. It can be seen from the scatter plot that the relationship between the green water fluxes based on the CRAE model after its parameters are calibrated and the green water fluxes from the water balance approach is even closer to the graph of $y=x$. Additionally, the accuracy of the CRAE model improved for all three types of forest after parameter calibration, with the value of $d$ reaching 0.98 and the value of $C_{D}$ increased to over 0.9 . The values of RMSE for R. pseudoacacia, P. orientalis, and P. tabulaeformis forests increased by $0.42 \mathrm{~mm}$, $0.22 \mathrm{~mm}$, and $0.50 \mathrm{~mm}$, respectively. Additionally, the values of NRMSE increased by $2 \%, 1 \%$, and $2 \%$, respectively, reaching the excellent level.

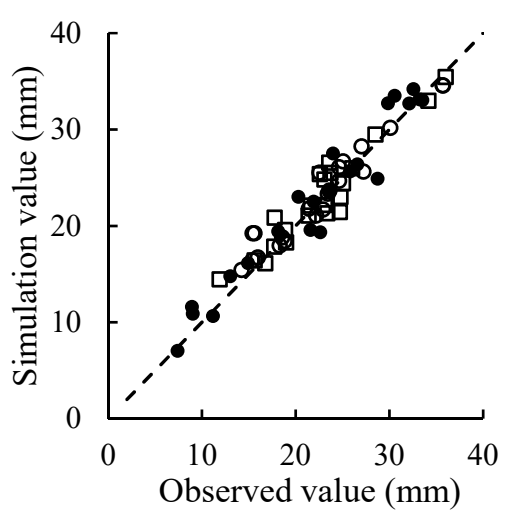

(a)

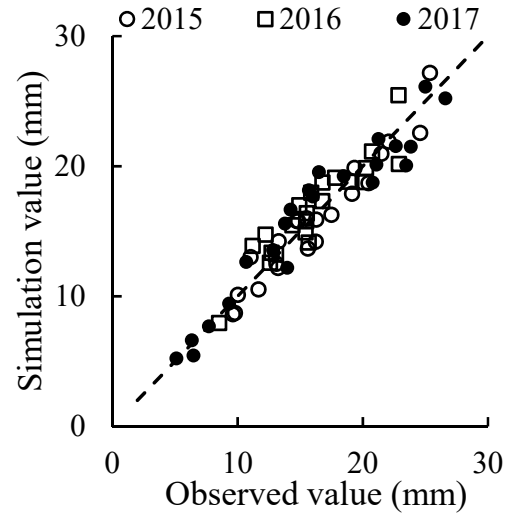

(b)

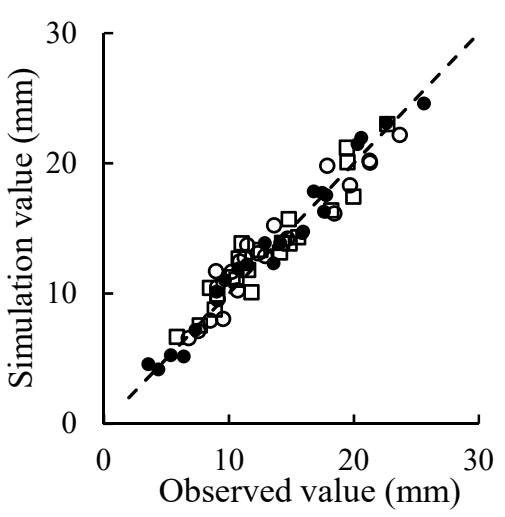

(c)

Figure 7. Scatter plot of simulated values of green water fluxes of (a) Robinia pseudoacacia, (b) Platycladus orientalis, and (c) Pinus tabulaeformis based on the CRAE model with calibrated parameters and green water fluxes derived from the water balance approach between 2015 and 2017.

Table 4. Simulation accuracy of green water fluxes based on the CRAE model with calibrated parameters between 2015 and 2017.

\begin{tabular}{ccccc}
\hline Vegetation & $\boldsymbol{d}$ & $\boldsymbol{C}_{\boldsymbol{D}}$ & RMSE $(\mathbf{m m})$ & NRMSE (\%) \\
\hline Robinia pseudoacacia & 0.98 & 0.93 & 1.77 & 7 \\
Platycladus orientalis & 0.98 & 0.91 & 1.50 & 7 \\
Pinus tabulaeformis & 0.98 & 0.94 & 1.26 & 6 \\
\hline
\end{tabular}




\subsection{Separation of Green Water Fluxes Based on CRAE Model at a Daily Timescale}

Based on the CRAE model with calibrated parameters and the dual crop coefficients of the three types of forests, the productive and non-productive green water for different types of vegetation were derived for the growing seasons of 2015 to 2017 (Figure 8). It can be seen that the monthly productive and non-productive green water fluxes that were estimated by the model were consistent with the corresponding values calculated by the water balance approach and the results from monitoring, which significantly increased during the growing season and reached its maximum at the middle stage before it started to drop at the final stage of the growing season. The non-productive green water flux was large at the beginning of the growing season and then slightly decreased during this period. It dropped again during the middle stage until it started to rise at the final stage of the growing season. However, non-productive green water flux significantly increased from Day 94 to 109 in 2017. The total green water fluxes rose at the beginning of the growing season, which remained at a high level during the middle stage until the final stage, when green water fluxes started to decline.
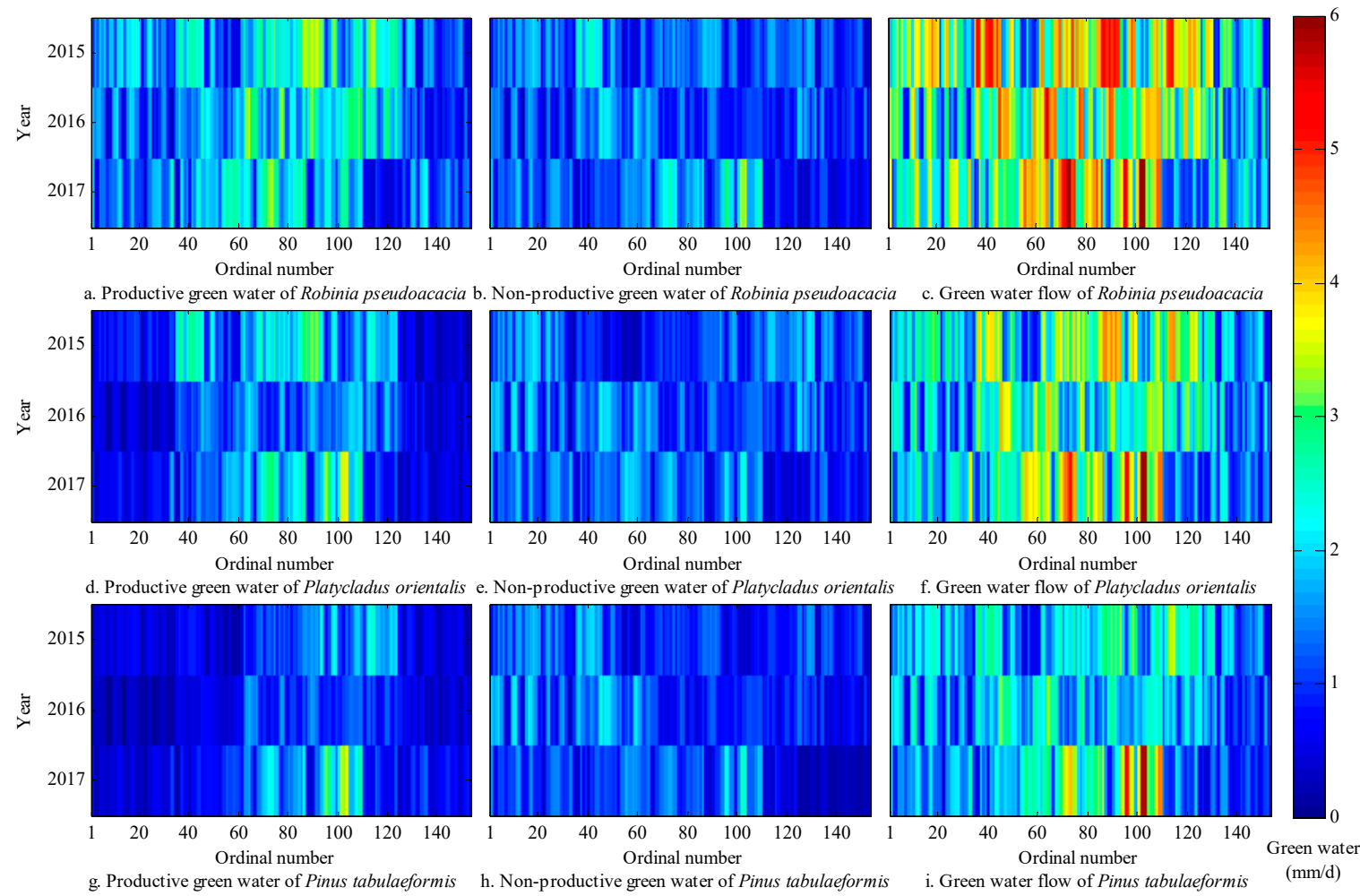

Figure 8. Green water flux separation results for three different types of vegetation during the growing season from 2015 to 2017.

In 2016, the precipitation in the Nanxiaohegou sub-basin was evenly distributed across the growing season. Therefore, the productive green water, non-productive green water, and green water flux were fluctuating less for the three types of vegetation. However, due to heavy rainfall, productive green water, non-productive green water, and total green water flux increased from Day 94 to 109 of the studied period in 2017 for three types of vegetation. According to the results of green water flux separation that are based on the CRAE model, the productive green water, non-productive green water, and green water flux of the R. pseudoacacia were the highest, followed by those of the P. orientalis, and the three values of the P. tabulaeformis were the lowest during the growing season between 2015 and 2017. Moreover, the productive green water of the P. orientalis from Day 1 to 36 and of the P. tabulaeformis from Day 1 to 63 of the studied period was significantly lower than the non-productive green water. 


\section{Discussion}

Precipitation is the only source of green water in the studied area. The average precipitation between 1954 and 2017 was $104.6 \mathrm{~mm}$ and $90.5 \mathrm{~mm}$ for August and September, respectively. However, the precipitation in these two months was $215.0 \mathrm{~mm}$ and $14.7 \mathrm{~mm}$ in 2017, which significantly differed from the average value. This significant variation from average precipitation somewhat influenced the amount of green water resource. In August 2017, when the precipitation was significantly higher than the average, the soil was unable to store more water over a short time, and thus most of the precipitation was converted to blue water, which would not make a significant contribution to an increase in green water storage. On the other hand, in September 2017, when the precipitation was much lower than the average, there was an ongoing consumption of green water storage due to plant transpiration and soil evaporation. According to the precipitation data between 2015 and 2017, the precipitation of 2015 was normal, while it was drier than normal in 2016 and wetter in 2017. Therefore, the temporal change in green water during the growing season of 2015 could reflect the general rule of green water change in this area; i.e., the productive green water increases first and then drops between May and September, and the non-productive green water changes in an opposite way.

In this study, we found that the crop coefficient of the R. pseudoacacia was the highest among the three types of vegetation, followed by that of the P. orientalis and P. tabulaeformis forests. This finding is consistent with the conclusions from a previous study carried out by Wang et al. [24]. Our research indicates that the proportion of precipitation that was converted to green water was the highest in the R. pseudoacacia forest, but it was much lower in the other two forests. This lower conversion rate stemmed from weaker transpiration due to the factors of stomatal frequency and aperture and the weaker plant interception that is caused by the smaller leaf area index of P. orientalis and P. tabulaeformis. Therefore, the green water fluxes of these two forests were lower than that of the R. pseudoacacia and the values of $K_{c}$ for these two forests were also smaller during the growing season. The value of $K_{c b}$ did not rise with the increase of temperature during the growing season, which is consistent with Xu's [25] findings on the transpiration characteristics of the main tree species that were used for soil and water conservation in the loess area of western Shaanxi. Plant photosynthesis may become reduced as a protection mechanism during the hottest period of the year when the radiation from the sun is strongest, thereby reducing transpiration. However, water-use efficiency is the highest during this period.

According to the evaluation of the applicability of the three complementary relationship-based models, the CRAE model was assessed as excellent for all three forests and the models of AA and Granger have good applicability to the forests. This is because, when simulating the evaporation to transpiration ratio and the radiation component of potential evapotranspiration, linear functions are adopted in the AA model, which are only suitable for a climate that is not too dry or too humid. However, the climate of the studied area is quite dry and thus the AA model has lower applicability. As for the Granger model, its linearization of the climatic and soil factors also results in certain limitations. In addition, the studied period spanned over the years of 2015, 2016, and 2017, which were normal, dry, and humid in terms of precipitation, respectively. Therefore, this research could reveal the features of green water flux in this region under different climate conditions. However, due to the limited observation cycles, further research on model applicability is required for specific hydrological conditions in order to assess the practicability and usefulness of the model.

According to different evaluation indicators, the CRAE model is the most accurate in calculating the crop transpiration in the studied area. After calibration, the CRAE model has improved accuracy in estimating the actual evapotranspiration for all three types of forests. Crop $R_{n}$ is affected by leaf area index (LAI), leaf angle distribution (LAD), and other factors. Our team used the canopy to measure the LAI of three planted forests during the experiment. The conclusion is that the LAI of the three crops are different, which also leads to different $R_{n}$ values. At the same time, $R_{n}$ value is not involved in this calibration process. The $b_{1}$ and $b_{2}$ value rate criteria are detailed in Chapter 3.4. The initial value of the $b_{1}$ parameter given in CRAE's model is $14 \mathrm{~W} / \mathrm{m}^{2}$, but the range of timing change of rate 
can only be determined according to experience, and the effect of its parameters cannot be studied in depth. We will do further study of this problem in the next stage of our research. Xu and Singh [15] evaluated the complementary relationship-based models with calibrated parameters in estimating evapotranspiration in different regions and found that the calibration of parameters could improve the accuracy, which is consistent with the results of this paper. From the physical meaning of the CRAE model, parameter $b_{1}$ is related to net solar radiation, but the relationship between them was not examined. In future research, a model can be built to describe the relationship between net solar radiation on different underlying surfaces and the CRAE parameters, which will allow the CRAE model to consider more factors in calculating green water flux, thereby improving simulation accuracy.

Evapotranspiration is the amount of green water that is consumed to maintain the stability of an ecosystem. Green water resources play a crucial role in the ecological environment. Stronger plant transpiration means more productive green water, which improves the ecological environment. Meanwhile, the higher proportion of soil evaporation in the non-productive green water could improve air humidity, which will facilitate the maintenance of ecosystem stability. In the future, a reasonable ratio between productive and non-productive green water resources could be determined based on general water resources (including green water resources), which could significantly improve the ecological environment.

\section{Conclusions}

The interannual variability in the total amount of green water during the growing season is low for all three types of planted forests. The trend of green water during the growing season is consistent with the precipitation, with the monthly amount of green water increasing from May to July and decreasing from August to September. The maximum monthly value during the studied period occurred in August 2017, with the amount of green water for the forests of R. pseudoacacia, P. orientalis, and P. tabulaeformis at $172.0 \mathrm{~mm}, 167.3 \mathrm{~mm}$, and $165.7 \mathrm{~mm}$, respectively. However, unlike the total amount of green water, the monthly productive green water flux changes in an inverted "V" shape with the month. The amount of monthly non-productive green water changes in a "V" shape. The green water stored in the forests of R. pseudoacacia and P. orientalis is mostly negative, demonstrating greater soil water extraction than recharge. The green water that was stored by the P. tabulaeformis is relatively large and the soil water extraction is relatively small; thus, the soil water content is relatively stable.

$K_{c b}$ for the three forests significantly increased from the small value in the early part of the growing season to its maximum value in the middle of the growing season. During the final stage of the growing season, $K_{c b}$ decreased slightly. $K_{e}$ was large at the beginning of the growing season, but it dropped with continuing growth of the forest until the final stage of the growing season when it started to increase. However, being affected by the continuous heavy rainfall in August 2017, $K_{e}$ significantly increased during the whole growing season, with its peak value occurring at the final stage of the growing season for all the forests, which were $0.75,0.53$, and 0.55 for the R. pseudoacacia, P. orientalis, and $P$. tabulaeformis, respectively. $K_{c}$ rose at the beginning of the growing season and it remained at a high level during the middle stage, before it started to decline in the final stage of the growing season. The R. pseudoacacia forest had the largest crop index, followed by the forests of P. orientalis and P. tabulaeformis.

The CRAE model has the best applicability and the highest accuracy for the calculation of green water of the three planted forests in the Nanxiaohegou sub-basin, which can meet the needs of the green water flux simulation in the studied area and can be used as a recommended method for simplifying the green water flux in the area. After parameter calibration for the three planted forests, the CRAE model can meet the further requirements of green water flux simulation for different types of vegetation. The productive and non-productive green water estimated by this model at a daily timescale and the monthly green water are consistent with the corresponding values being derived from water balance approach and monitoring. 
The precipitation distributed evenly across the growing season of 2016, and the fluctuations in productive green water, non-productive green water, and total green water flux were very small for all types of vegetation. However, the productive green water, non-productive green water, and total green water flux increased for all three types of vegetation in 2017 due to heavy rainfall from Day 94 to 109 of the studied period. The significant variation in precipitation between August and September in 2017 in the studied area resulted in the inability of the soil to store more water in a short time, as most of the precipitation contributed to the blue water, which was not conducive to the storage of green water and it could increase soil erosion in the studied area.

The R. pseudoacacia had the productive green water, non-productive green water, and green water flux during the growing season between 2015 and 2017, followed by the P. orientalis and the P. tabulaeformis forests. Moreover, the productive green water of the P. orientalis from Day 1 to 36 and the P. tabulaeformis from Day 1 to 63 of the studied period was significantly lower than the non-productive green water. The variation in productive green water that was caused by the rapid change in precipitation differs from each other for the three planted forests, with the lowest variation in productive green water occurring in the R. pseudoacacia. This finding indicates that the change of meteorological conditions had the smallest impact on the transpiration of $R$. pseudoacacia in the studied area.

Author Contributions: Conceptualization, N.F. and X.S.; methodology, N.F.; investigation, N.F., L.X. and L.L.; resources, H.L. and Y.L.; data curation, L.L., H.L. and Y.L.; writing-original draft preparation, N.F. and X.S.; writing - review and editing, L.X., L.L., H.L. and Y.L.; visualization, N.F.; supervision, X.S.; project administration, L.X.; funding acquisition, X.S.

Funding: This research was funded by the National Natural Science Foundation of China, grant number 41771259.

Acknowledgments: The authors thank the staff of the Xifeng Scientific Experiment Station of Soil and Water Conservation for their assistance as well as Shengyu Cui, Yuchao Qin, Xianghua Feng and Ling Zhang from Xi'an University of Technology, China and Mingming Guo, Hongliang Kang and Qianhua Shi from Northwest A\&F University, China for help in the field. We also sincerely thank the reviewers who contributed their expertise and time on reviewing this manuscript.

Conflicts of Interest: The authors declare no conflict of interest.

\section{References}

1. Zang, C.F.; Liu, J.G.; Jiang, L.; Gerten, D. Influence of human activities and climate variability on green and blue water provision in the Heihe River Basin, NW China. J. Water Clim. Change 2015, 6, 800-815. [CrossRef]

2. Falkenmark, M.; Rockström, J. The new blue and green water paradigm: breaking new ground for water resources planning and management. J. Water Resour. Plann. Manag.-ASCE 2006, 132, 129-132. [CrossRef]

3. Schieremeier, Q. Water: A long dry summer. Nature 2008, 452, 270-273. [CrossRef]

4. Zuo, D.P.; Xu, Z.X.; Peng, D.Z.; Song, J.X.; Cheng, L.; Wei, S.K.; Abbaspour, K.C.; Yang, H. Simulating spatiotemporal variability of blue and green water resources availability with uncertainty analysis. Hydrol. Process. 2015, 29, 1942-1955. [CrossRef]

5. Rockström, J. On-farm green water estimates as a tool for increased food production in water-scarce regions. Phys. Chem. Earth 1999, 24, 375-383. [CrossRef]

6. Liu, J.G.; Yang, H. Spatially explicit assessment of global consumptive water uses in cropland: green and blue water. J. Hydrol. 2010, 384, 187-197. [CrossRef]

7. Bulcock, H.H.; Gushb, M.B.; Jewitta, G.P.W. A comparison of productive and non-productive green water-use efficiency of Podocarpus henkelii and Pinus patula in the KwaZulu-Natal Midlands. South. For. 2014, 76, 75-84. [CrossRef]

8. Lawrence, D.M.; Thornton, P.E.; Oleson, K.W.; Bonan, G.B. The partitioning of evapotranspiration into transpiration, soil evaporation, and canopy evaporation in a GCM: Impacts on land-atmosphere interaction. J. Hydrometeorol. 2007, 8, 862-880. [CrossRef]

9. Liu, J.G. Consumptive water use in cropland and its partitioning: A high-resolution assessment. Sci. Chin. Ser. E Technol. Sci. 2009, 52, 3309-3314. [CrossRef] 
10. Xu, J.X. Increasing trend of green water coefficient in the middle Yellow River basin and the eco-environmental implications. Acta Ecol. Sin. 2015, 35, 7298-7307. (In Chinese)

11. Lin, C.Q.; Zhou, T.Y.; Ren, L.L.; Jiang, S.H.; Liu, Y.; Gong, L.Y. Advances in methods for green water assessment. Water Resour. Prot. 2014, 30, 85-89. (In Chinese)

12. Liu, W.B.; Wang, L.; Zhou, J.; Li, Y.Z.; Sun, F.B.; Fu, G.B.; Li, X.P. A worldwide evaluation of basin-scale evapotranspiration estimates against the water balance method. J. Hydrol. 2016, 538, 82-95. [CrossRef]

13. Michael, W.; Marilyn, G.; Haw, Y.; Jeff, A.; Daren, H.; Chinnasamy, S.; Richard, H. Regional Blue and Green Water Balances and Use by Selected Crops in the U.S. J. Am. Water Resour. Assoc. 2016, 51, 1626-1642.

14. Bouchet, R.J. Evapotranspiration réelle et potentielle, signification climatique. Int. Assoc. Hydrol. Sci. 1963, 62, 134-142.

15. Xu, C.Y.; Singh, V.P. Evaluation of three complementary relationship evapotranspiration models by water balance approach to estimate actual regional evapotranspiration in different climatic regions. J. Hydrol. 2005, 308, 105-121. [CrossRef]

16. Allen, R.G.; Pereira, L.S.; Raes, D.; Smith, M. Crop Evapotranspiration. Guidelines for Computing Crop Water Requirements; FAO (Food and Agriculture Organization): Rome, Italy, 1998.

17. Jia, H.K.; Liu, Y.H.; Xia, X.; Wang, K.; Gao, Q. Simulation of soil water dynamics iv a Caragana Intermedia woodland in Huangfuchuan watershed: relationships among slope, aspect, plant density and soil water content. Acta Phytoecologica 2005, 29, 910-917.

18. Er-Raki, S.; Chehbouni, A.; Boulet, G.; Williams, D.G. Using the dual approach of FAO-56 for partitioning ET into soil and plant 1 components for olive orchards in a semi-arid region. Agric. Water Manag. 2010, 97, 1769-1778. [CrossRef]

19. Tong, G.D.; Liu, H.L.; Li, F.H.; Yang, S.L.; Fan, H.Y. Reliability Evaluation of Dual Crop Coefficient Approach on Evapotranspiration Calculation of Peach Tree in North China. Trans. Chin. Soc. Agric. Mach. 2016, 47, 154-162.

20. Morton, F.I. Operational estimates of areal evapotranspiration and their significance to the science and practice of hydrology. J. Hydrol. 1983, 66, 1-76. [CrossRef]

21. Brutsaert, W.; Stricker, H. An advection-aridity approach to estimate actual regional evapotranspiration. Water Resour. Res. 1979, 15, 443-450. [CrossRef]

22. Granger, R.J. A complementary relationship approach for evaporation from nonsaturated surfaces. J. Hydrol. 1989, 111, 31-38. [CrossRef]

23. Batton, I.J. A Parameterization of the evaporation from nonsaturated surfaces. J. Appl. Meteorol. 1979, 18, $43-47$.

24. Wang, J.X.; Huang, B.L.; Wang, M.C.; Wang, D.H. Transpiration water consumption of young Platycladus orientalis and Robinia pseudoacacia trees and their correction functions under different water supply. Chin. J. Appl. Ecol. 2005, 16, 419-425. (In Chinese)

25. $\mathrm{Xu}$, J.J. Studies on photosynthesis and transpiration characteristics of tree major species for soil and water conservation in Loess Plateau of Northern Shaanxi. Master's Thesis, Beijing Forestry University, Beijing, China, 2012. (In Chinese)

(C) 2019 by the authors. Licensee MDPI, Basel, Switzerland. This article is an open access article distributed under the terms and conditions of the Creative Commons Attribution (CC BY) license (http://creativecommons.org/licenses/by/4.0/). 